\title{
5-LIPOXYGENASE INHIBITOR (ZILEUTON) PRODUCES ANTI-DEPRESSION EFFECT IN STRESS INDUCE CRS MICE MODEL
}

\author{
SAPTARSHI PANIGRAHI ${ }^{1}$, SOMNATH SURAI ${ }^{2}$, HAO HONG $^{1 *}$
}

${ }^{1}$ Department of Pharmacology, Key Laboratory of Neuropsychiatric Diseases, China Pharmaceutical University, Nanjing 210009, China. ${ }^{2}$ Department of Pharmaceutics, Key Laboratory of Natural Medicines, China Pharmaceutical University, Nanjing 210009, China.

Email: saptarshi@stu.cpu.edu.cn

Received: 21 November 2019, Revised and Accepted: 28 December 2019

\section{ABSTRACT}

Objective: The experiment aimed to find out the effectiveness of Zileuton, a 5-LOX inhibitor on depressive behavior and neuroinflammation in vivo.

Method: Male ICR mice (25-30g) randomly distributed Veh+Veh, CRS+Vehicle, CRS+ZIL50, and CRS+ZIL100. Zileuton was orally given in the treatment groups for 21 days after 3 weeks of stress induce CRS model. Starting from the day 1, in CRS model, mice were immobilized 8 hr/day for consecutive 21 days to induce stress. After completing the drug administration, subjected the mice for behavioral tests, and then performed histopathological \& Western Blotting.

Result: Stress induces CRS model guide to the significant depressive-like behavior of the mice in behavioral tests which was united by adverse changes at the cellular/molecular level responsible for regulation of inflammatory and apoptotic processes. CRS triggered Microglial over activation in the DG of the hippocampus, which was successfully inhibited by Zileuton post-treatment at the dose of $100 \mathrm{mg} / \mathrm{kg}$ than $50 \mathrm{mg} / \mathrm{kg}$. Level of TNF- $\alpha$, IL$1 \beta$, nuclear NF- $\mathrm{B}$ p 65 , Bax, and cleaved Caspase- 3 was high and Bcl-2 expression was low in the stress induce CRS -treated mice which were found to be opposite in the Zileuton $(100 \mathrm{mg} / \mathrm{kg}$ ). However, the dose of $50 \mathrm{mg} / \mathrm{kg}$ less to mimic the effects as exhibited more by the $100 \mathrm{mg} / \mathrm{kg}$ dose of Zileuton.

Conclusion: It can be concluded that selective 5-lipoxygenase inhibitor Zileuton can efficiently inhibit the depressive-like behavior/activity in CRSinduced depressive mouse model. The study is the first to show the role of 5-lipoxygenase enzyme in and Chronic Restraint Stress (CRS)-induced mice models of stress, anxiety or depression.

Keywords: Depression, Zileuton, 5-lipoxygenase, Neuroinflammation, Apoptosis.

(C) 2020 The Authors. Published by Innovare Academic Sciences Pvt Ltd. This is an open access article under the CC BY license (http://creativecommons. org/licenses/by/4. 0/) DOI: http://dx.doi.org/10.22159/ajpcr.2020.v13i2.36501

\section{INTRODUCTION}

Although the full mechanism of the pathogenesis of depression is not well known, depression is known to be associated with complex emotional disorders related to neurohormones pathway.

Nowadays, the development of animal models provides an inner view to determine the mechanism responsible for the onset and inclined of the depressive disorder. Chronic stress is a risk factor for emotional and psychiatry-related diseases such as depression [1]. Stress is considered among the critical issues for the growing up of mental disorders such as cognitive dysfunction and depression. Exposure to recurrent and longtime stress may tend to activate the hypothalamic-pituitary-adrenal axis (HPA) and sympathoadrenomedullary (SAM) system [2]. After that, the level of corticosterone (CORT) is inclined by the activity of the HPA axis, which further affected cognitive function. On the opposite side, the SAM system raises catecholamine levels to enhance the fear reflex during stress. Studies have exposed that chronic restraint stress (CRS) in the mice results in abnormal neurobehavioral activities such as anxiety, depression, and cognitive impairment. In addition, restraint stress can also induce oxidative/nitrite stress, pro-inflammatory cytokine release, increased expression of cyclooxygenase-2, and activation of activated $\mathrm{NF}-\kappa \mathrm{B}$ in different brain regions.

Accumulating evidence belief that chronic and repeated restraint stress expose to directs the changes in hippocampal morphology, function, and volume. Chronic stress-induced neuronal cell loss and apoptotic cell death in the hippocampal region are mainly responsible for the development of illness of depression and cognitive impairment [3].
Therefore, it is urgently needed to identify and develop new alternative therapies for the treatment of depression and its associated mood disorders. More and more evidence from human and mouse models suggest that inflammation is a key factor in the pathogenesis of depression. Significantly, pro-inflammatory cytokines mainly interleukin-1 $\beta$ (IL-1 $\beta$ ) and tumor necrosis factor- $\alpha$ (TNF- $\alpha$ ) increase in cerebrospinal fluid and blood in patients with depression.

Furthermore, administration of IL-1 $\beta$, IL- 6 , and TNF- $\alpha$ can show depressive and anxiety-like behaviors in animal models. In addition, pre-treatment of endogenous IL-1 receptor antagonists [4] able to prevent behavioral defects in the helpless model of acquired depression.

These provide substantial proof with the causal link between inflammation and depression. Cysteinyl leukotrienes including LTC4, LTD4, and LTE4 are inflammatory lipid mediators derived from the 5-lipoxygenase (5-LOX) pathway of the arachidonic acid metabolism [5].

In this research experiment, we find out the activity of 5-LOX drug zileuton $(50 \mathrm{mg} / \mathrm{kg}$ and $100 \mathrm{mg} / \mathrm{kg})$ treatment on the tail suspension test (TST), forced swimming test (FST), novelty-suppressed feeding teat (NSFT), and open field test (OFT) in mice that repeatedly exposed to CORT. At present, many evidence recommended that neuroinflammation plays a key role in the pathophysiology of depression [6]. High levels of pro-inflammatory cytokines such as IL-1 $\beta$ and TNF- $\alpha$ showed significantly in depression patients [7]. Plasticity and neurotransmission were affected by these cytokines, thus inhibiting the neurogenesis in the brain, and the administration of antidepressants suppresses these cytokines activation. The conversion 
of arachidonic acid to 5-hydroperoxyeicosatetraenoic acid is carried out in the presence of a pro-inflammatory enzyme named 5-LOX and afterward the catalysis; it also produces hydroxyeicosatetraenoic acid. Therefore, it metabolized in several leukotrienes [8]. 5 LOX as well as the leukotrienes in the CNS perform both neuromodulatory and neuroendocrine effects [9] and lead to inflammatory response characterized by the increments of IL-1 $\beta-T N F-\alpha$, and NF- $\kappa$ B. Recently, a large number of researchers focused on 5 LOX. 5-LOX has intensified as its novel pathophysiological role in several types of CNS injury, such as cerebral ischemia, cognitive deficits, traumatic brain injury, and anxiety $[10,11]$. However, the relationship, as well as the mechanism between 5 LOX and depressive-like behaviors, needs to be clarified. In this experiment, we first observed whether 5-LOX inhibitor zileuton prevents depressive behaviors and neuroinflammatory responses to stress (CRS)-induced mice model.

In addition, we also analyze whether the behavioral antidepressantlike effects of zileuton were associated with changes in hippocampal cell proliferation and neuronal commitment, as well as alteration of astrocytic hyperactivation.

\section{METHODS}

\section{Animals study design}

Institute of Cancer Research (ICR) mice (ICR) were used for these experiments, took 12 mice in each group. All experiments were conveyed according to the NIH guide for the care and use of Laboratory Animals (NIH publications No. 80-23, received, 1996) and animal care committee in China Pharmaceutical University approved the procedure. All animals were placed on a 12-h dark/light cycle with free access to water and standard chow and adapted for 1 week before the start of the experiment.

The experimental design has depicted in Fig. 1.

Group-1 was not provided with any stress but administered normal saline for 21 days before behavioral and biochemical estimation. Normal control group assigned to this group.

Group-2 restrained [12] the animals ( $8 \mathrm{~h} /$ day for 42 days), but not provided drugs or vehicle treatment. This group was assigned as a model group.

Group-3 animals were restrained stress ( $8 \mathrm{~h} /$ day for 42 days) and treated with zileuton $(50 \mathrm{mg} / \mathrm{kg}$, intragastric [i.g.]) for the past 21 days. Group-4 animals were restrained ( $8 \mathrm{~h} /$ day for 42 days) and treated with zileuton $(100 \mathrm{mg} / \mathrm{kg}$, i.g.) for the past 21 days. The study plan is described graphically in Fig. 2. The animals were restrained for $8 \mathrm{~h}$ daily, up to 28 consecutive days using $50 \mathrm{ml}$ polystyrene tubes. The drug treatment was started on the $22^{\text {nd }}$ day of the study and continued up to the $28^{\text {th }}$ day. 2 hours before the restraint stress exposure drugs was induced by ig. route. Animals randomly divided into four groups: Vehicle+Vehicle normal physiological saline (Veh+Veh), CRS+Vehicle CRS+Veh, CRS+Zileuton $50 \mathrm{mg} / \mathrm{kg}$, CRS+Zileuton $100 \mathrm{mg} / \mathrm{kg}$. Zileuton
(50 mg/kg or $100 \mathrm{mg} / \mathrm{kg}$ ), and $0.2 \mathrm{ml} / 10 \mathrm{~g}$ of body weight, dissolved in methanol ( $0.5 \%$ methanol) and physiological saline was orally given in mice daily by i.g. route after 21 days, subjected the mice to behavioral tests. After the behavioral tests, the mice were sacrificed by cervical dislocation, and the brain was taken out for immunohistochemistry (IHC), Western blotting (WB).

\section{Behavior tests}

FST

The FST was performed [13]. In short, separately placed the mice were separately placed in glass cylinder (diameter $19 \mathrm{~cm}$, and height $25 \mathrm{~cm}$ ) containing water $\left(25 \pm 1^{\circ} \mathrm{C}\right)$ to a depth of $13 \mathrm{~cm}$ and allowed to swim for $6 \mathrm{~min}$. The behavior of the mice was recorded and explored by TSE behavioral software. After a 6 min test, the mice were removed from the tank and thoroughly dried with a dry cloth then returned to the colony room in their home cage. Change the tank's water after each swim session. The immobility time as the absence of active, unwanted behavior, such as jumping, swimming, rearing, or diving was judged. The total immobility time during final 4 min of a 6 min test season was measured by an observer blind to the treatment conditions.

\section{TST}

TST was performed [14]. After FST mice were conducted $24 \mathrm{~h}$. Shortly, the mice were moved from the housing room to the testing room in their home cages, at least $1 \mathrm{~h}$ before testing to allow for adapt to the new environment. During the dark period of the circadian cycle, mice were tested. Each mouse was hanged by the tail with adhesive tape to the hook in the soundproof box. The total immobility period during 6-min test was explored by ANY-MAZE software. The immobility period during the initial 2 min of the 6 min task was discounted while the past 4 min task was explored statistically.

OFT

The OFT was performed [15]. The mice were conducted $24 \mathrm{~h}$ after TST. The open field contained $(40 \times 40 \times 38 \mathrm{~cm})$ square arena with a clean Plexiglass wall and floor. At first, the mouse was placed in one corner of the open space and during a 5-min test, the session allowed to move the arena freely. Peripheral and central activities using a computer-assisted activity system with software to easily the data collection and analysis were measured.

NSFT

After habituation in the testing room, mice were subjected to the novelty suppression-feeding test [16]. The testing instrument consists of a plastic box $(50 \times 50 \times 20 \mathrm{~cm})$, covered by a wooden bed $2 \mathrm{~cm} .24 \mathrm{~h}$ before this behavioral test, all food was removed from their cage. At testing time, a single pellet of food was placed on a white paper platform in the center of the testing box. The mouse has placed at the center of the box. The mouse was placed in the corner of the box and instantly started the stopwatch. The latency to eat (it means the mouse sitting on its haunches and biting the pellet with the use of forepaws) was recorded.

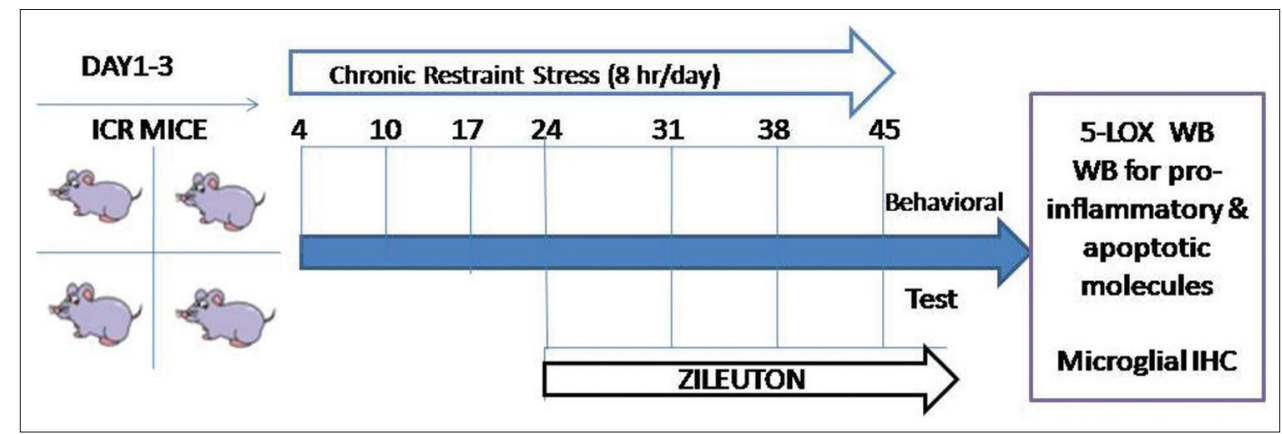

Fig. 1: Experimental design of 5-LOX (zileuton) inflammatory, apoptotic study 


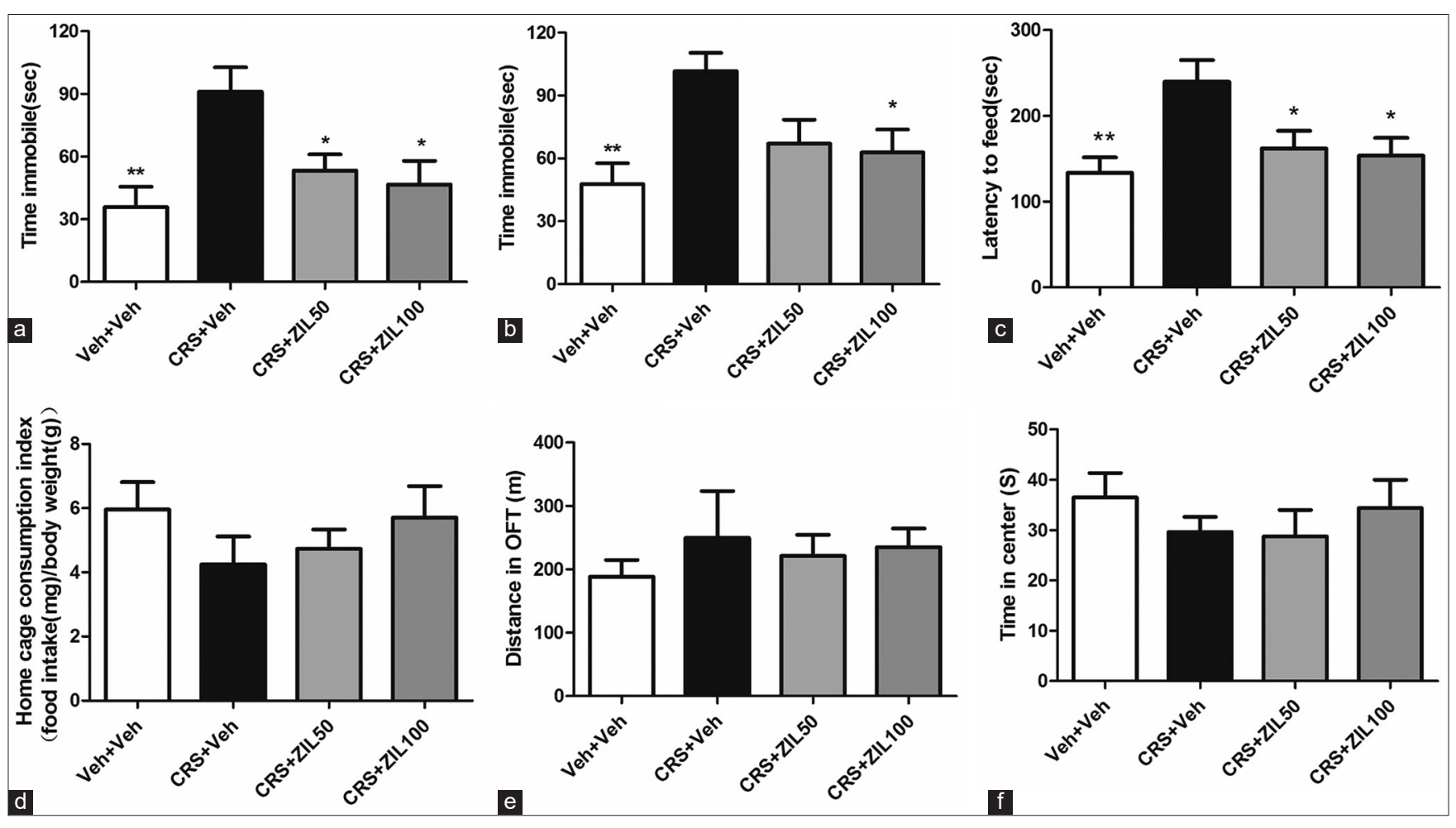

Fig. 2: Zileuton prevents chronic restraint stress-induced depression-related behaviors. (a) Immobility time in tail suspension test, (b) immobility time in forced swimming test, (c) latency to feed, (d) home cage consumption index in novelty-suppressed feeding teat, (e) total distance and (f) time in center in open field test were shown. The data are illustrated as mean \pm S.E.M $(n=8) .{ }^{*} p<0.05,{ }^{* *} p<0.01$ vs. CORT+Veh group

\section{Tissue preparation and immunohistochemical analyses}

Tissue preparation, at the first anesthetized the mice and perfused transcardially with $0.1 \mathrm{M}$ phosphate-buffered saline (PBS) (pH-7.4), contains $4 \%$ paraformaldehyde and $5 \mathrm{U} / \mathrm{ml}$ heparin. Then, the brain was collected and fixed in $4 \%$ paraformaldehyde for $18 \mathrm{~h}-20 \mathrm{~h}$ followed by $30 \%$ sucrose solution for $24 \mathrm{~h}$. After then, the brain was dissected and embedded into optimal tissue cutting (optimal cutting temperature) compound on dry ice and cryosectioned at $30 \mu \mathrm{m}$. Following the manufacturer's instructions, immunohistochemical staining was performed using the Streptavidin-Biotin Complex (SABC) IHC kit. After washing the section with $0.1 \mathrm{M}$, PBS solution heated the sections on a water bath for $4 \mathrm{~h}$ in $0.3 \%$ Triton $\mathrm{X}-100$ at $60^{\circ} \mathrm{C}$. Then again, washed the section and treated with $3 \% \mathrm{H}_{2} \mathrm{O}_{2}$ at normal room temperature for $10 \mathrm{~min}$ and washed with PBS for $3 \times 5$ min followed by blocking $5 \%$ bovine serum albumin (BSA) for $30 \mathrm{~min}$. After then, the sections were incubated overnight at $4^{\circ} \mathrm{C}$ with primary antibody for Iba1 (rabbit IgG, 1:1000) diluted in 5\% BSA. The next day, washed the sections in PBS for $3 \times 5 \mathrm{~min}$ at room temperature and incubated with biotinylated mouse anti-rabbit IgG for $20 \mathrm{~min}$. After then, again rewashed in PBS $\left(3 \times 5 \mathrm{~min}, 37^{\circ} \mathrm{C}\right)$ and incubated with the $\mathrm{SABC}$ at $37^{\circ} \mathrm{C}$ for $20 \mathrm{~min}$. Again, sections were washed in $0.1 \mathrm{M}$ PBS for $4 \times 5 \mathrm{~min}$ and mounted on the glass slides then added the diaminobenzidine followed by gradient dehydration $(1.70 \%$ ethanol for $5 \mathrm{~min}, 2.95 \%$ ethanol for $5 \mathrm{~min}, 3.100 \%$ ethanol for $2 \times 5 \mathrm{~min}$, and 4 xylene for $2 \times 5 \mathrm{~min}$ ). The next sections were covered with DPX mounting solution and cover glass. At last, photomicrographs were obtained using a Nikon DS-Fi2 camera connected to a Nikon Eclipse Ti microscope and analyzed by the Image-Pro Plus software.

\section{Total protein and nuclear protein extraction}

Homogenized the mouse hippocampus in an ice-cold RIPA buffer, it contains $0.1 \%$ phenylmethylsulfonyl fluoride (PMSF). The homogenate was centrifuged at $12,000 \mathrm{~g}$ for $15 \mathrm{~min}$ and collected the supernatant to determine the total protein concentration. The supernatant was used to determine using the $\mathrm{BCA}$ protein kit and stored at $-20^{\circ} \mathrm{C}$.
Nucleoprotein extraction kit was used for nuclear extraction. Shortly, chopped the mouse hippocampus into small pieces, then homogenized in the ice-cold hypotonic buffer, contains $1 \%$ PMSF, $0.5 \%$ phosphate inhibitor, $0.1 \%$ DL-Dithiothreitol (DDT), and then centrifuged at $4^{\circ} \mathrm{C}$ $3000 \mathrm{~g}$ for $5 \mathrm{~min}$. Then washed the precipitate with hypotonic buffer solution and centrifuged at $4^{\circ} \mathrm{C}, 5000 \mathrm{~g}$ for $5 \mathrm{~min}$. Finally, $0.2 \%$ lysis buffer containing $1 \%$ PMSF, $0.1 \%$ DDT, and $0.5 \%$ phosphatase buffer was added into the precipitate, cooled for $20 \mathrm{~min}$ and centrifuged at $4^{\circ} \mathrm{C}, 15,000 \mathrm{~g}$ for $10 \mathrm{~min}$. Subjected the supernatant nuclear extract was detected by WB assay for NF- $\mathrm{kB}$ p65 and histone $\mathrm{H} 3$ using as the control.

\section{Immunofluorescence staining}

Taken the brain slices and washed with 0.1 M PBS solution for $5 \mathrm{~min} \times 3$ times. Then treated with $3 \% \mathrm{H}_{2} \mathrm{O}_{2}$ at normal room temperature for $30 \mathrm{~min}$ and washed with PBS for $5 \mathrm{~min} \times 3$ times after then treated with $0.3 \%$ Triton X-100 for 15 min washed again for $5 \mathrm{~min} \times 3$ times. Blocking serum $(10 \%$ goat serum $+5 \%$ fetal bovine serum $+2 \%$ BCA diluted by PBST) was incubated at room temperature for $1 \mathrm{~h}$ and blocked serum was not washed. Added anti-5-LOX (1:100) and incubated overnight at $4^{\circ} \mathrm{C}$. Next day, washed the sections in PBS for $5 \mathrm{~min} \times 3$ times and treated with secondary antibody (1:200) at room temperature for $1 \mathrm{~h}$ and avoid light. At last, sections were covered with DPX mounting solution and cover glass. Finally, visualized the sections in a fluorescence microscope and analyzed the data.

\section{Western blot analysis}

Evaluation of protein, the sample was run and isolates the protein bands by sodium dodecyl sulfate polyacrylamide gel electrophoresis. Then transferred the bands onto polyvinylidene fluoride membrane and blocked with $5 \%$ skim milk prepared in Tris-buffered saline solution. Membranes were incubated at $4^{\circ} \mathrm{C}$ overnight with the respective primary antibody for 5 -LOX (1:1000), IL-1 $\beta$ (1:500), TNF- $\alpha$ (1:500), Caspase-3 (1:1000), Bcl-2 (1:200), and Bax (1:1000); $\beta$-actin (1:3000) was used as control. 
For NF- $\mathrm{KB}$ p65 (1:1000), Histone H3 (1:500) loading control. After the overnight incubation, membranes were washed with Tris-buffered saline-tween 20 and incubated for $2 \mathrm{~h}$ at room temperature, with a horseradish peroxidase-conjugated secondary antibody (1:50001:10000). Finally, the antibody reactive bands were visualized using enhanced chemiluminescence detector reagents (1:1) by gel imaging system.

\section{Statistical analysis}

Data shown are expressed as mean \pm standard error of mean using analysis of variance (ANOVA) software to analyze the behavioral tests (TST, OFT, FST, and NFST). All other data were analyzed by oneway ANOVA for various comparisons, followed by Dennett's post hoc analyzer. All analyses were carried out using SPSS v20.0. Considered the $p<0.05$ was significantly different between the groups.

\section{RESULTS}

Zileuton prevent CRS stress-induced depressive behaviors

To assess that 5-LOX inhibition prevents stress (CRS)-induced depression-related behaviors, we treated the mice using zileuton a 5-LOX inhibitor and performed different behavior tests. As expected, the mice exposed to stress (CRS) displayed to rise immobility time in the TST (Fig. 2a, F(3,36)=5.503, p<0.01). Treatment with zileuton (50 mg/ $\mathrm{kg}$ or $100 \mathrm{mg} / \mathrm{kg}$ ) significantly decreased the immobility time in the TST (Fig. 2a, CRS+Zil50, and CRS+Zil100: $\mathrm{p}<0.05$ ) in comparison to the stress (CRS)-induced group. Similarly, same result was obtained in the FST. In compare with the Veh+Veh group, mice induced with stress (CRS), spent long immobility time (Fig. $2 \mathrm{~b}, \mathrm{~F}(3,36)=4.929$, $\mathrm{p}<0.01$ ), and this was diminished by zileuton treatment $(50 \mathrm{mg} / \mathrm{kg}$ or $100 \mathrm{mg} / \mathrm{kg}$ ) (Fig. 2b, CRS+Zil100 p<0.05). Furthermore, evaluated the anxietyrelated behavior using NSFT, in which mice displayed an increases in the latency to feed in the novel environment (Fig. 2c, $F(3,36)=4.798$, $\mathrm{p}<0.01$ ) while no changes were noticed in home cage consumption index (Fig. 2d, F(3,36) $=0.931$, p>0.05) after stress (CRS) and zileuton treatment $(50 \mathrm{mg} / \mathrm{kg}$ or $100 \mathrm{mg} / \mathrm{kg}$ ) suppressed the latency to feed in stress (CRS)-induced mice (Fig. 2c CRS+Zil50 and CRS+Zil100: $\mathrm{p}<0.05$ ). In the OFT, the locomotor activities were observed, and there were no changes among groups (Fig. $2 \mathrm{e}, \mathrm{F}(3,36)=0.333$, $\mathrm{p}>0.05$; Fig. $2 \mathrm{f}$, $F(3,36)=0.613, p>0.05$. Moreover, this research also expressed that zileuton $(50 \mathrm{mg} / \mathrm{kg}$ and $100 \mathrm{mg} / \mathrm{kg}$ ) administration reduced depressive behavioral abnormalities in compare to stress (CRS)-induced depressive mice model. Taken together, zileuton a 5-LOX inhibitor can significantly prevent stress (CRS)-induced depressive-like behavior.

\section{5-LOX enzyme present in stress (CRS)-induced mouse model}

It was confirmed that exposure to stress can increase basolateral amygdala (BLA), dentate gyrus (DG), CA1, and CA3 in the brain. The primary function of BLA, DG, CA1, and CA3 is stimulating fear response. The fear system is intended to avoid the pain of injury. This research expressed that 5-LOX is elevated in CA3 exposed stress mice in comparison to normal mice (Figs. $3 a$ and $b, F(3,12)=6.162$, $p<0.05$ ). Fig. 3 shows that 5 -LOX was increased in stress-induced mouse model.

Zileuton normalized microglial activation in the hippocampus of stress mice

It has been reported that CRS mediates neuroinflammatory response through the microglial activation, which undergoes an alteration characterized by cell numbers enhancement and conformational changes, including size enlargement and thicker processes [17]. To investigate the effects of hippocampal 5-LOX on microglia, we detected the levels of microglial activation by the immunohistochemical method. Fig. 4 shows stress (CRS)-induced significantly increased that the number of Iba1+cells in the hippocampus of mice (Figs. 4a and b, $F(3,12)=10.096, p<0.01)$ is compared with the Veh+Veh group, and

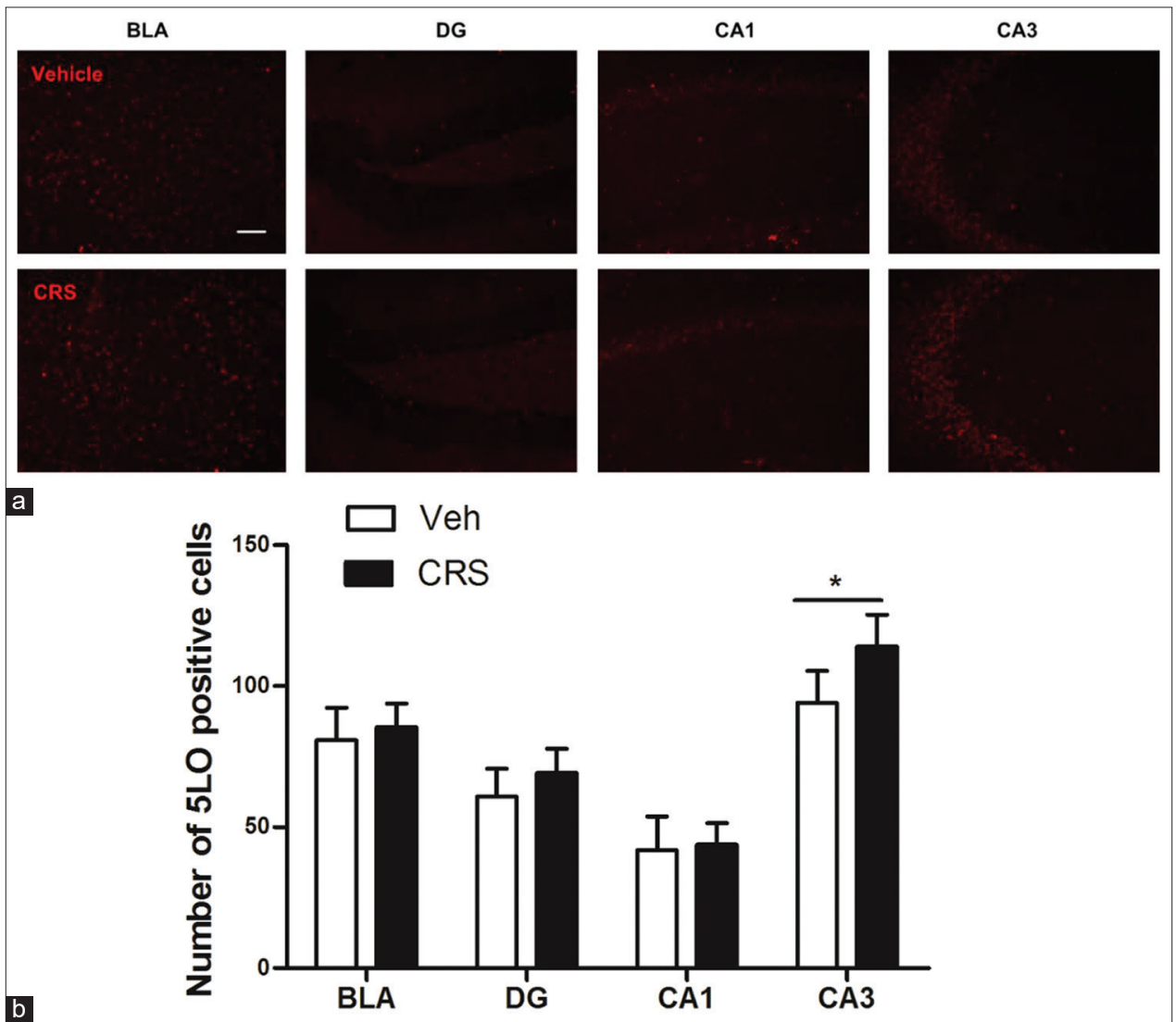

Fig. 3: Distribution of 5-lipoxygenase (5-LOX) in mouse brain. (a) Detection of 5 LOX expression in dentate gyrus, CA1, CA3, and basolateral amygdala. (b) Quantification of the number of 5-LOX positive cells. The results are expressed as mean \pm standard error of mean $(\mathrm{n}=4) .{ }^{*} \mathrm{p}<0.05,{ }^{* *} \mathrm{p}<0.01$ versus Vehicle group 
zileuton $(50 \mathrm{mg} / \mathrm{kg}$ or $100 \mathrm{mg} / \mathrm{kg}$ ) significantly reduced the amount of Iba1-staining cells (Fig. 4b CRS+Zil50 and CRS+Zil100: $\mathrm{p}<0.01$ ). These data indicate that 5-LOX inhibitors zileuton obstructs stress (CRS)induced microglial activation.

Zileuton weakens NF- $\mathrm{kB}$ signaling and pro-inflammatory cytokines in stress (CRS)-induced mice

Evidence has shown that 5-LOX mediates inflammatory response by regulating the NF- $\mathrm{KB}$ pathway [18], and stress (CRS) activated the NF- $\mathrm{BB}$ pathway by triggering the nuclear translocation of the thep65 subunit. Here, we are curious about whether 5-LOX is involved in the CORT-activated NF- $\mathrm{kB}$ pathway. Interestingly, in the hippocampus, the NF- $\kappa \mathrm{B}$ signals were significantly inhibited after the treatment of (5-LOX inhibitor) zileuton (50 mg/kg or $100 \mathrm{mg} / \mathrm{kg}$ ) (Figs. $5 \mathrm{a}$ and b, $\mathrm{F}(3,12)=11.465, \mathrm{p}<0.05)$, able block the expression of hippocampal 5 LOX (Fig. 5b, CRS+Zil50: $p<0.05$ and CRS+Zil100: $p<0.01$ ).
Activated microglia and the NF- $\mathrm{BB}$ pathway could regulate various neurotoxic mediators and pro-inflammatory cytokines involved in the pathogenesis of depression [19]. To investigate the effect of zileuton on the neuroinflammatory process induced by stress (CRS), proinflammatory cytokines such as IL- $1 \beta$ and TNF- $\alpha$ were analyzed by Western blot analysis. Figure 5 shows stress (CRS) exposure significantly increased the generations of TNF- $\alpha$ and IL- $1 \beta$ in the hippocampus (Fig. 5c, $F(3,12)=13.67, p<0.01$; Fig. 5e, $F(3,12)=6.259, p<0.05)$, whereas zileuton $(50 \mathrm{mg} / \mathrm{kg}$ or $100 \mathrm{mg} / \mathrm{kg}$ ) suppressed to produced TNF- $\alpha$ and IL-1 $\beta$ (Fig. 5d, F CRS+Zil50: $p<0.05$ and CRS+Zil100: $\mathrm{p}<0.01$ ). These results indicate that 5 -LOX inhibitor prevents stress (CRS)-induced production of pro-inflammatory cytokines.

\section{Zileuton prevents neuronal apoptosis}

Evidence has shown that 5-LOX decreases pro-apoptotic molecules such as cleaved Caspase-3, and Bax and TUNEL in the mouse hippocampus
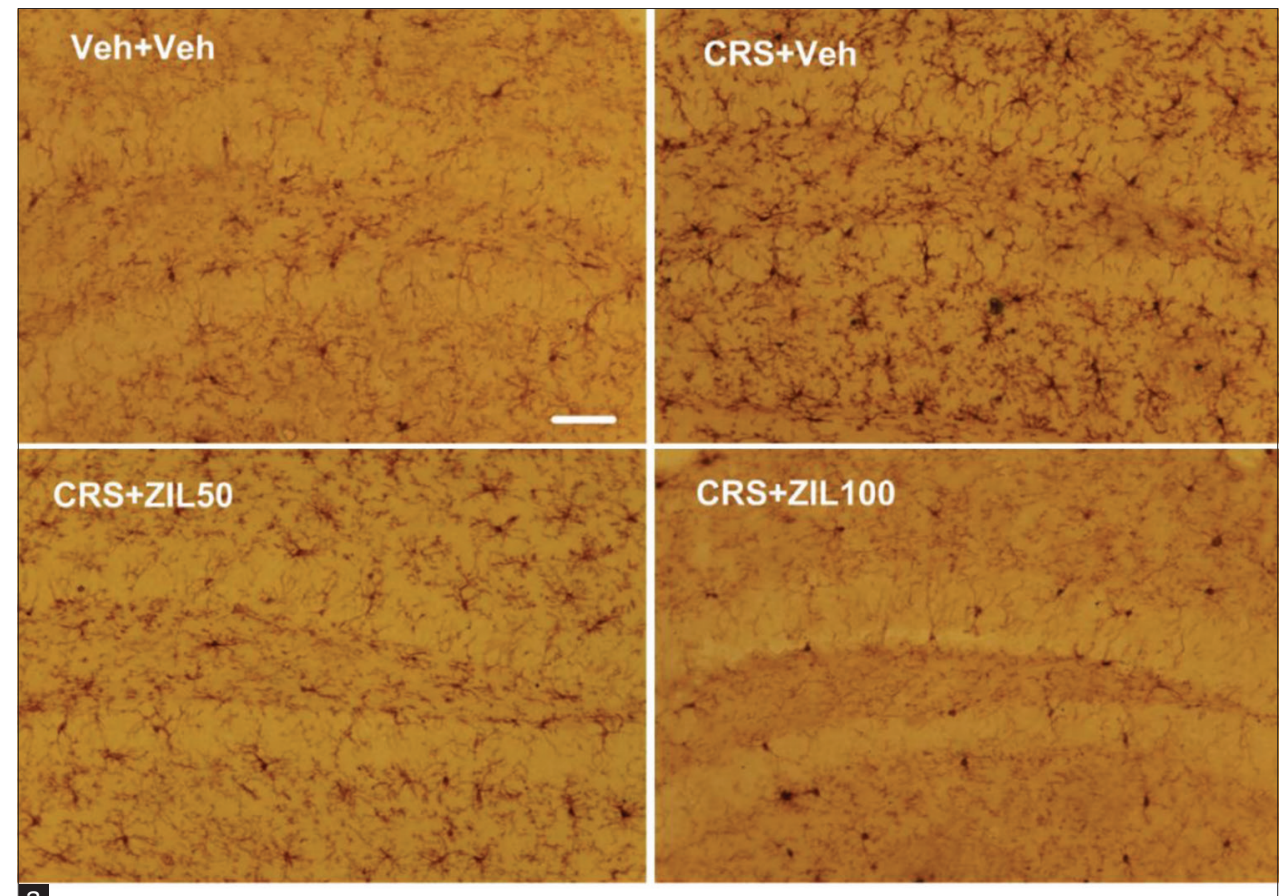

a
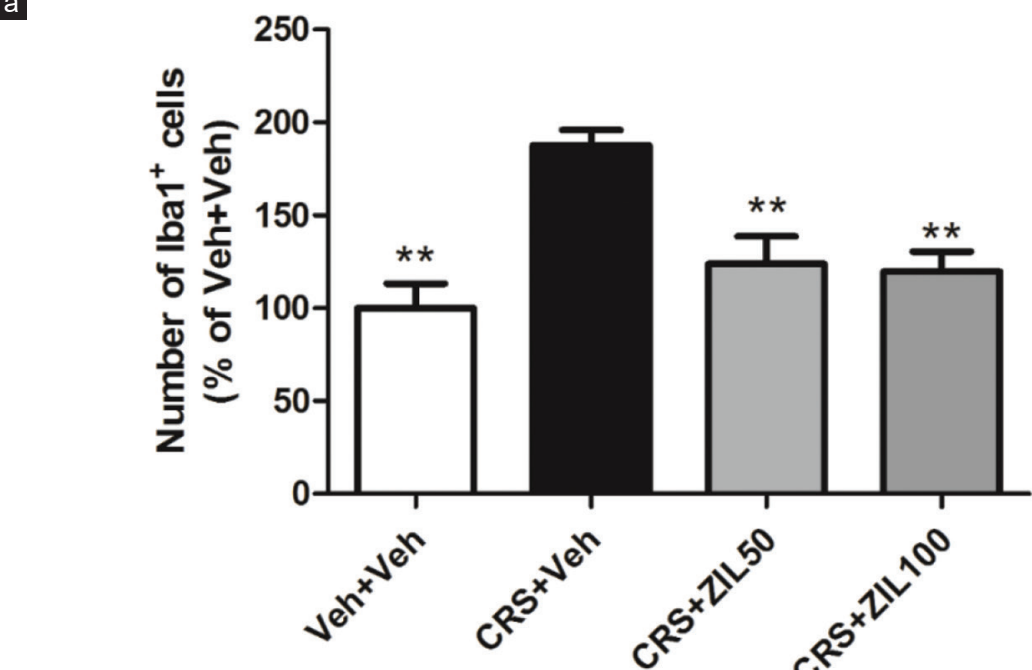

b
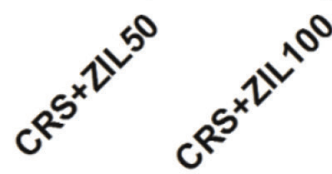

Fig. 4: Microglial activation in the hippocampus of stress (chronic restraint stress [CRS])-induced mice is normalized by zileuton. Mice were sacrificed and brain sections were immunohistochemical staining for the microglial marker Iba1. (a) Representative immunohistochemical microphotographs of Iba1+microglial cells in the dentate gyrus, scale bar $50 \mu \mathrm{m}$; (b) quantification of integrated optical density of the Iba1 + microglial cells. (Values shown are expressed as mean \pm standard error of the mean; $\mathbf{n}=3$. ${ }^{* *} \mathrm{p}<0.01^{* * *} \mathrm{p}<0.001$ vs. CRS+Veh group) 


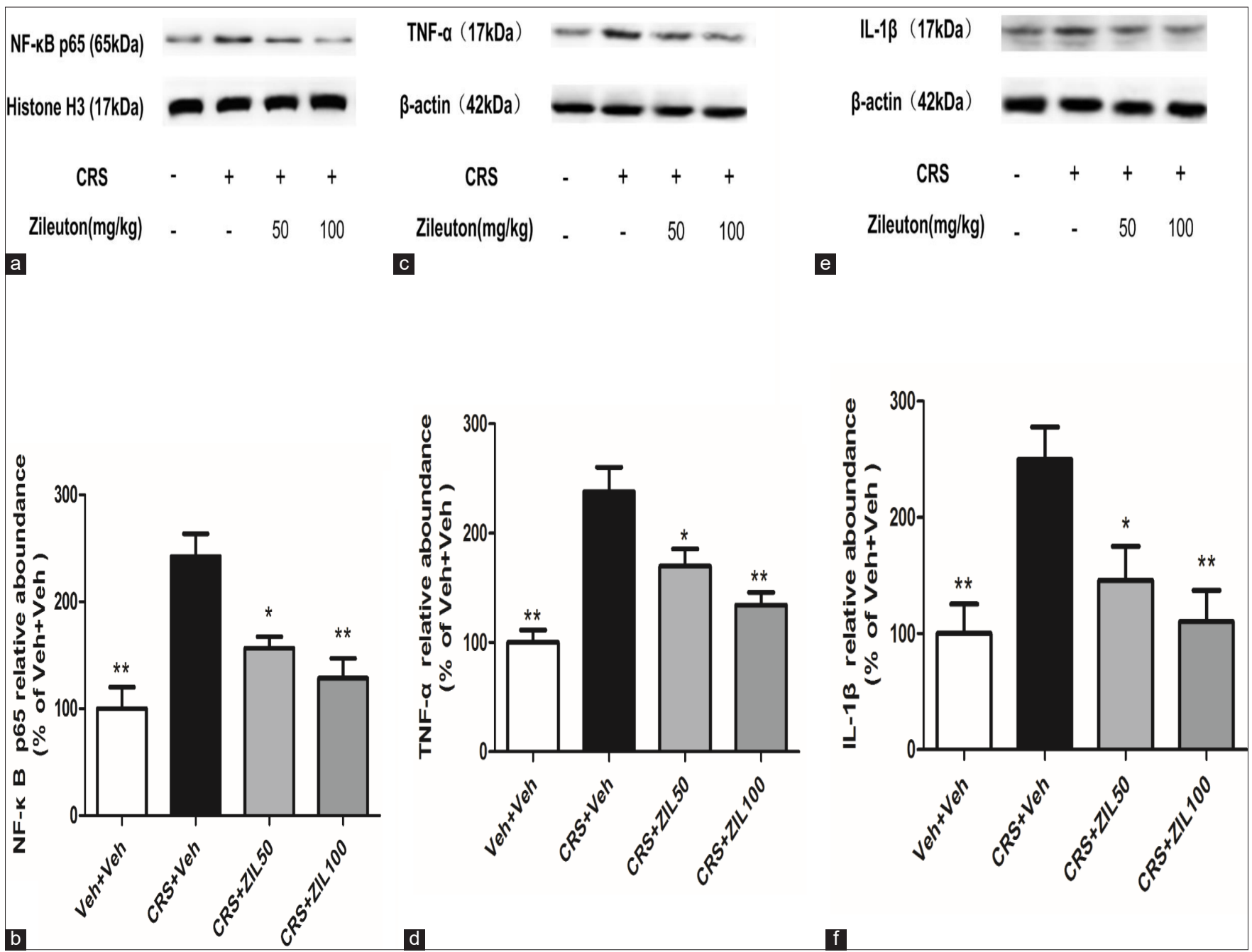

Fig. 5: Zileuton weakens NF-кB signaling and pro-inflammatory cytokines in stress (CRS) induced mice.The protein expression of hippocampal 5LOX , (a,b) nuclear NF- $\mathrm{kB}$ p65, (c,d) TNF- $\alpha$, (e,f) IL-1 $\beta$ and $\beta$-actin or histone H3 as loading control were examined by western blot using respective antibodies (1:1000). Quantification of expressed as the ratio (in \%) of Veh+Veh group are shown. The data are expressed as mean \pm S.E.M $(n=4) .{ }^{*} \mathbf{p}<0.05,{ }^{* *} \mathrm{p}<0.01$ vs. CRS+Veh group.

while the level of the anti-apoptotic protein Bcl-2 was increased. Fig. 6a (Fig. 6a, $\mathrm{F}(3,12)=10.255$, $\mathrm{p}<0.01$ ) shows that zileuton (more $100 \mathrm{mg} / \mathrm{kg}$ than $50 \mathrm{mg} / \mathrm{kg}$ dose) decreases the expression of cleaved caspase- 3 in compare to stress (CRS)-induced mice model (Fig. 6b CRS+Zil50: $\mathrm{p}<0.05$ and CRS+Zil100: $\mathrm{p}<0.01$ ). Similarly, zileuton decreases the Bcl2/Bax ratio in comparison to stress (CRS)-induced mice model. (Fig. 6c, $F(3,12)=16.005, p<0.05$ ) (Fig. 6d CRS+Zil50: $p<0.05$ and CRS+Zil100: $\mathrm{p}<0.01$ ). In immunofluorescence assay, zileuton decreases neuronal apoptosis in TUNEL positive cells ratio in mouse hippocampus (Fig. 6e, $F(3,12)=8.763, p<0.05$ ) (Fig. 6f CRS+Zil50: $p<0.05$ and CRS+Zil100: $\mathrm{p}<0.01)$.

\section{DISCUSSION}

In this study, the preventive effect of 5-LOX inhibitor zileuton had shown in the CRS-induced depressive model with neuroinflammation and neuronal apoptosis. Stress (CRS)-induced in mice led to depressive and anxiety-like behaviors with the presence of pro-inflammatory cytokine elevation, activation of microglia, and imbalanced level of apoptotic regulation, which was accompanied, by an increased level of 5-LOX, $\mathrm{NF}-\kappa \mathrm{B}$ in the hippocampus of the mouse brain. Treatment with zileuton $(50 \mathrm{mg} / \mathrm{kg}$ and $100 \mathrm{mg} / \mathrm{kg}$ ) for 3 weeks effectively inhibited behavioral, histopathological, and biochemical changes by inducing stress (CRS). It produced several behavioral activities including increased immobility time in the FST and TST test and increased the latency to feed in the NSFT in mice. It was accompanied by the hippocampal inflammatory response, activated microglia, increased the expression of TNF- $\alpha$, IL-1 $\beta$, NF- $\kappa B$ p65, increased cellular apoptosis caspase-3, Bax, TUNEL, and decreased Bcl-2. 5-LOX inhibitor drug zileuton markedly attenuated these effects by inducing stress (CRS). These results suggesting that the antidepressant effect of 5-LOX inhibitor reduced neuroinflammation. Furthermore, increasing evidence suggested that a strong association in-between neuroinflammation and depression, which was marked by, increased levels of pro-inflammatory cytokines in the central nervous systems. The 5-LOX is broadly expressed in the central nervous system. It localizes mainly in neuronal cells $[8,20]$. In recent study had suggested in various regions of the brain, including the hippocampus. Where increase in its level. We first identified the expression of hippocampal 5-LOX in depressive mice model by induced stress (CRS), which was used to model inflammation with depressive disorders.

Therefore, we found that after the administration of zileuton produced an antidepressive effect in the behavioral tests, exhibited by inhibiting the CRS stress-induced increase in immobility time in the FST and TST and differences in locomotors activities by observed in OFT. In addition, depression often with anxiety in patients, so we estimated the anxietylike behaviors by the selecting of NSFT. Zileuton treatment significantly opposite the anxiety-like behaviors induced by stress (CRS), and 


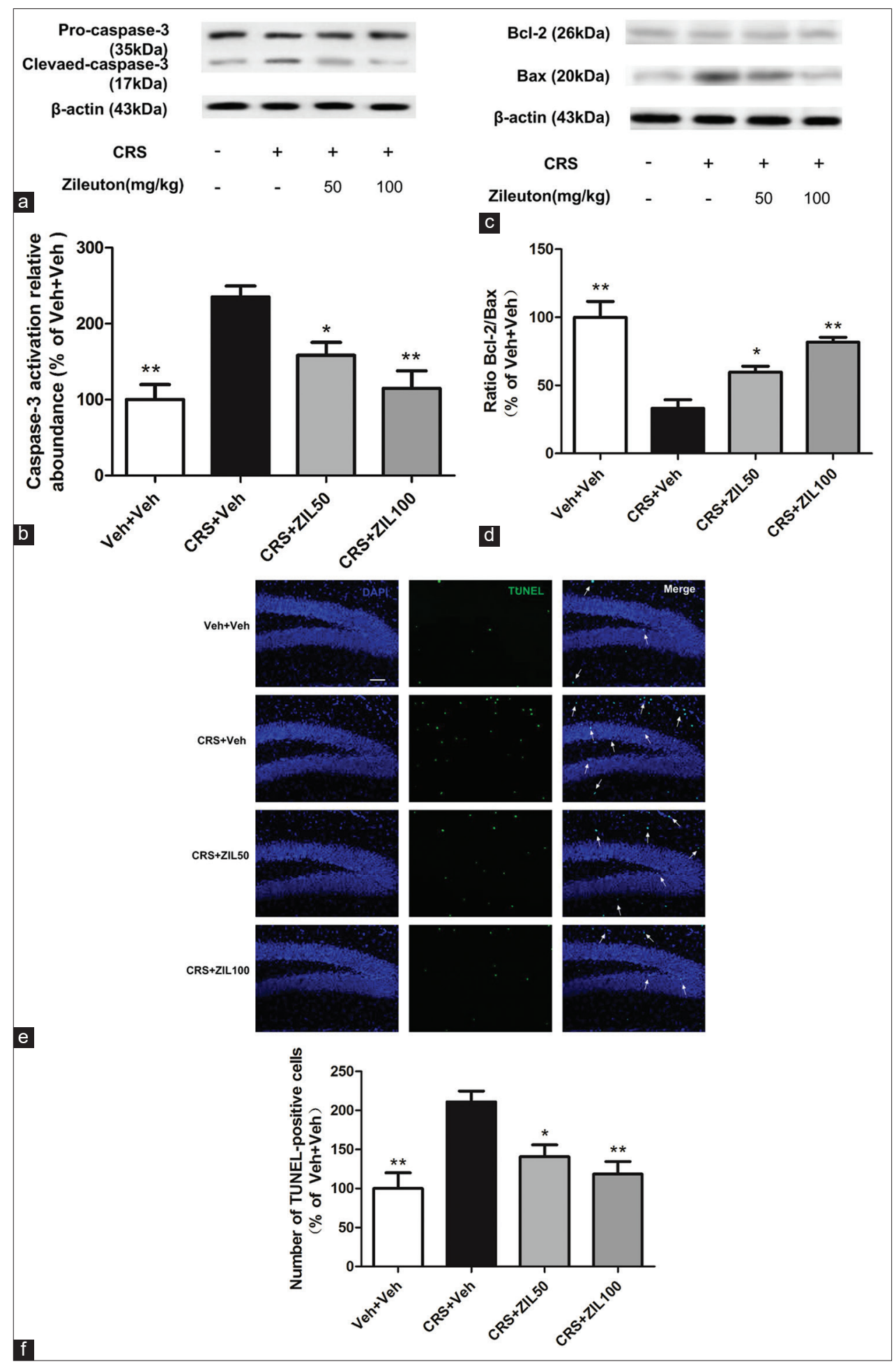

Fig. 6: Zileuton decreases the caspase 3 activation in CRS(Stress) -induced mice. Entire hippocampus extracts were adapted to western blot analysis via an antibody against caspase 3 , (a) pro-caspase $3 \&$ cleaved caspase 3 and (c) Bcl-2/Bax. Quantification of the protein levels of (b) caspase 3 and (d) Bcl-2/Bax was expressed as the ratio (in \%) of Veh+Veh group, (e,f) Entire hippocampus extracts were adapted to TUNEL staining by fluorescence microscopy. The results are revealed as mean \pm S.E.M $(n=4) . * P<0.05, * * P<0.01$ vs. CRS+Veh group

characterized by reducing the increment of latency to feed by stress (CRS). Moreover, zileuton exhibited an antidepressant effect.

Treatment with zileuton is one of the 5-LOX inhibitors, successfully attenuated histopathological and biochemical changes by induced chronic stress microglial associated neuroinflammation intraperitoneal route $[19,21]$. However, histological changes in microglia have considered being a pathophysiological role of depression [22]. 5-LOX effectively inflammatory mediator, which plays a crucial role in the asthma patient and other inflammatory diseases $[23,24]$.

The 5-LOX inhibitor, zileuton is a novel class of anti-asthma drugs and well tolerated in asthma patient [23,25]. 5-LOX mediated signaling is relative to NF- $\kappa B$ pathway [26-29]. NF- $\kappa B$, an important transcription factor, regulates expression of several pro-inflammatory cytokines such as TNF- $\alpha$ and IL-1 $\beta$ [30]. Therefore, NF- $\kappa B$ has reported 
mediate microglia activation and suppressing NF- $\mathrm{kB}$ transcriptional activity inhibits the production of pro-inflammatory cytokines [30]. Administration of zileuton $(50 \mathrm{mg} / \mathrm{kg}$ and $100 \mathrm{mg} / \mathrm{kg}$ ) regulated these pro-inflammatory cytokines through inhibition (TNF- $\alpha$ and IL-1 $\beta$ ) of NF-кB p65.

Evidence focus that apoptosis as an essential faction contributing depressive pathogenesis [31] not only inhibits the inflammatory reactions but also blocks the apoptotic processes as well [32].

In addition, microglia-derived TNF- $\alpha$ and IL-1 $\beta$ can mediate cell death [32]. Therefore, suppressing the NF- $\mathrm{kB}$ signaling and microglial activation is helpful against depression-related neuronal apoptosis. Earlier studies have shown that pro-apoptotic protein such as Bax, caspase-3, and antiapoptotic protein Bcl-2 is related in the depressive mice model and blocking NF- $\mathrm{KB}$ opposite changes in depressive mice [33].

In here, this experiment, increases in stress (CRS), caused an increment of pro-apoptotic molecules such as caspase-3, Bax, TUNEL immunofluorescence assay, and approximately Bcl-2 reduction in the mouse hippocampus. However, the treatment of zileuton $(50 \mathrm{mg} / \mathrm{kg}$ and $100 \mathrm{mg} / \mathrm{kg}$ ) significantly gives such a response in comparison to the model group. Hence, it concluded that 5-LOX can be a promising target for the treatment of depression.

\section{ACKNOWLEDGMENTS}

This work was supported by grants from the National Natural Science Foundation of China (81573413 and 81773714 to Hao Hong) and the Fundamental Research Funds for the Central Universities (2632017PT01). Saptarshi Panigrahi is a recipient of China Govt. Scholarship-Chinese University Program (China Scholarship Council) for foreign students at China Pharmaceutical University. Somnath Surai is a recipient of Master degree CSC scholarship at CPU.

\section{AUTHOR'S CONTRIBUTIONS}

Both authors have contributed to reviewing the preparation and editing of the manuscript.

\section{CONFLICTS OF INTEREST}

The authors declare that they have no conflicts of interest.

\section{REFERENCES}

1. Harvey BH, Brand L, Jeeva Z, Stein DJ. Cortical/hippocampal monoamines, HPA-axis changes and aversive behavior following stress and restress in an animal model of post-traumatic stress disorder. Physiol Behav 2006;87:881-90.

2. Zhang Y, Liu W, Zhou Y, Ma C, Li S, Cong B. Endoplasmic reticulum stress is involved in restraint stress-induced hippocampal apoptosis and cognitive impairments in rats. Physiol Behav 2014;131:41-8.

3. Ferraz AC, Delattre AM, Almendra RG, Sonagli M, Borges C, Araujo $\mathrm{P}$, et al. Chronic $\omega-3$ fatty acids supplementation promotes beneficial effects on anxiety, cognitive and depressive-like behaviors in rats subjected to a restraint stress protocol. Behav Brain Res 2011;219:116-22.

4. Kim KS, Han PL. Optimization of chronic stress paradigms using anxiety-and depression-like behavioral parameters. J Neurosci Res 2006;83:497-507.

5. Chaudhari N, Talwar P, Parimisetty A, Lefebvre d'Hellencourt C, Ravanan P. A molecular web: Endoplasmic reticulum stress, inflammation, and oxidative stress. Front Cell Neurosci 2014;8:213

6. Dantzer R, O'Connor JC, Freund GG, Johnson RW, Kelley KW. From inflammation to sickness and depression: When the immune system subjugates the brain. Nat Rev Neurosci 2008;9:46-56.

7. Liu Y, Ho RC, Mak A. Interleukin (IL)-6, tumour necrosis factor alpha $(\mathrm{TNF}-\alpha)$ and soluble interleukin-2 receptors (sIL-2R) are elevated in patients with major depressive disorder: A meta-analysis and metaregression. J Affect Disord 2012;139:230-9.

8. Rådmark $\mathrm{O}$, Werz $\mathrm{O}$, Steinhilber $\mathrm{D}$, Samuelsson B. 5-Lipoxygenase: Regulation of expression and enzyme activity. Trends Biochem Sci
2007;32:332-41.

9. Nakagawa Y, Chiba K. Role of microglial M1/M2 polarization in relapse and remission of psychiatric disorders and diseases. MDPI Pharm 2014:7:1028-48.

10. Giannopoulos PF, Chu J, Joshi YB, Sperow M, Li JG, Kirby LG, et al. Gene knockout of 5-lipoxygenase rescues synaptic dysfunction and improves memory in the triple-transgenic model of Alzheimer's disease. Mol Psychiatry 2014;19:511-8.

11. Joshi YB, Praticò D. Knockout of 5-lipoxygenase results in agedependent anxiety-like behavior in female mice. PLoS One 2011;6:e29448.

12. Chiba S, Numakawa T, Ninomiya M, Richards MC, Wakabayashi C, Kunugi H. Chronic restraint stress causes anxiety- and depressionlike behaviors, downregulates glucocorticoid receptor expression, and attenuates glutamate release induced by brain-derived neurotrophic factor in the prefrontal cortex. Prog Neuropsychopharmacol Biol Psychiatry 2012;39:112-9.

13. Porsolt RD, Martin $P$, Lenègre A, Fromage $S$, Drieu K. Effects of an extract of Ginkgo Biloba (EGB 761) on "learned helplessness" and other models of stress in rodents. Pharmacol Biochem Behav 1990;36:963-71.

14. Cryan JF, Mombereau C, Vassout A. The tail suspension test as a model for assessing antidepressant activity: Review of pharmacological and genetic studies in mice. Neurosci Biobehav Rev 2005;29:571-625.

15. Baitharu I, Jain V, Deep SN, Kumar G, Ilavazhagan G. Exposure to hypobaric hypoxia and reoxygenation induces transient anxiety-like behavior in rat. J Behav Brain Sci 2013;3:519-602.

16. Santarelli L, Saxe M, Gross C, Surget A, Battaglia F, Dulawa S, et al. Requirement of hippocampal neurogenesis for the behavioral effects of antidepressants. Science 2003;301:805-9.

17. Graeber MB, Streit WJ. Microglia: Biology and pathology. Acta Neuropathol 2010;119:89-105.

18. Kazmi SM, Plante RK, Visconti V, Taylor GR, Zhou L, Lau CY. Suppression of NF kappa B activation and NF kappa B-dependent gene expression by tepoxalin, a dual inhibitor of cyclooxygenase and 5-lipoxygenase. J Cell Biochem 1995;57:299-310.

19. Tanuma N, Sakuma H, Sasaki A, Matsumoto Y. Chemokine expression by astrocytes plays a role in microglia/macrophage activation and subsequent neurodegeneration in secondary progressive multiple sclerosis. Acta Neuropathol 2006;112:195-204.

20. Zhao CZ, Zhao B, Zhang XY, Huang XQ, Shi WZ, Liu HL, et al. Cysteinyl leukotriene receptor 2 is spatiotemporally involved in neuron injury, astrocytosis and microgliosis after focal cerebral ischemia in rats. Neuroscience 2011;189:1.

21. Huang XJ, Zhang WP, Li CT, Shi WZ, Fang SH, Lu YB, et al. Activation of CysLT receptors induces astrocyte proliferation and death after oxygen-glucose deprivation. Glia 2008:56:27-37.

22. Kawano T, Matsuse H, Kondo Y, Machida I, Saeki S, Tomari S, et al. Cysteinyl leukotrienes induce nuclear factor kappa $\mathrm{b}$ activation and RANTES production in a murine model of asthma. J Allergy Clin Immunol 2003;112:369-74

23. Raison CL, Lowry CA, Rook GA. Inflammation, sanitation, and consternation: Loss of contact with coevolved, tolerogenic microorganisms and the pathophysiology and treatment of major depression. Arch Gen Psychiatry 2010;67:1211-24.

24. Ul Ain Q, Greig NH, Nawaz MS, Rashid S, Kamal MA. Exploring $\mathrm{N}(1)$-p-fluorobenzyl-cymserine as an inhibitor of 5-lipoxygenase as a candidate for type 2 diabetes and neurodegenerative disorder treatment. CNS Neurol Disord Drug Targets 2014;13:197-202.

25. Thompson C, Cloutier A, Bossé Y, Thivierge M, Gouill CL, Larivée P, et al. CysLT1 receptor engagement induces activator protein-1-and NF-kappaB-dependent IL-8 expression. Am J Respir Cell Mol Biol 2006;35:697-704.

26. Wang XY, Tang SS, Hu M, Long Y, Li YQ, Liao MX, et al. Leukotriene D4 induces amyloid- $\beta$ generation via CysLT(1)R-mediated NF- $\mathrm{KB}$ pathways in primary neurons. Neurochem Int 2013;62:340-7.

27. Sethi G, Sung B, Aggarwal BB. Nuclear factor-kappaB activation: From bench to bedside. Exp Biol Med (Maywood) 2008;233:21-31.

28. Ye SM, Johnson RW. Regulation of interleukin-6 gene expression in brain of aged mice by nuclear factor kappaB. J Neuroimmunol 2001;117:87-96

29. Stadelmann C, Deckwerth TL, Srinivasan A, Bancher C, Brück W, Jellinger $\mathrm{K}$, et al. Activation of caspase-3 in single neurons and autophagic granules of granulovacuolar degeneration in Alzheimer's disease. Evidence for apoptotic cell death. Am J Pathol 1999;155:1459-66

30. Rohn TT, Vyas V, Hernandez-Estrada T, Nichol KE, Christie LA, 
Head E. Lack of pathology in a triple transgenic mouse model of Alzheimer's disease after overexpression of the anti-apoptotic protein Bcl-2. J Neurosci 2008;28:3051-9.

31. Tusi SK, Ansari N, Amini M, Amirabad AD, Shafiee A, Khodagholi F. Attenuation of NF-kappaB and activation of Nrf2 signaling by 1,2,4-triazine derivatives, protects neuron-like PC12 cells against apoptosis. Apoptosis 2010;15:738-51.
32. Lawrence T, Gilroy DW, Colville-Nash PR, Willoughby DA. Possible new role for NF-kappaB in the resolution of inflammation. Nat Med 2001;7:1291-7.

33. Lepley RA, Fitzpatrick FA. 5-Lipoxygenase compartmentalization in granulocytic cells is modulated by an internal bipartite nuclear localizing sequence and nuclear factor kappa B complex formation. Arch Biochem Biophys 1998;356:71-6. 